\title{
Effects of Opiate Dependence Through Different Administration Routes on Pulmonary Inflammation and its Severity
}

\author{
Mohammad Masoomi 1,* , Marzieh Tajoddini ${ }^{1}$, Gholamabbas Mohammadi ${ }^{1}$, Reza \\ Malekpoor ${ }^{1}$, Ebrahim Abasi ${ }^{1}$ \\ ${ }^{1}$ Cardiology Department, Kerman University of Medical Sciences, Kerman, IR Iran \\ *Corresponding author: Mohammad Masoomi, Cardiology Department, Kerman University of Medical Sciences, Kerman, IR Iran. Tel/Fax: +98-5117332137, E-mail: drmasoomio8@ \\ gmail.com
}

Received: August 21, 2012; Accepted: January 08, 2013

\begin{abstract}
Background: Serious health problems and socioeconomic consequences of the illicit use of opiates have been proved in both developed and developing societies.

Objectives: We aimed to evaluate "The effects of opiate addiction through different administration routes on pulmonary inflammation and its severity."

Materials and Methods: Our experiments were performed on eighteen adult male Syrian golden hamsters which were allocated to one of the three groups $(n=6)$ : control group which did not receive opiate; the first study group were administered oral opiate via stomach tube; and another study group were administered inhaled opiate. After four weeks, all hamsters were anesthetized with diethyl ether and their lung tissues were isolated for pathological assessment.

Results: Severe perivascular inflammation was detected in $33.3 \%$ of the samples with oral opiate dependence and $20 \%$ of the cases addicted to opiate through inhalation. Also, severe peribronchial inflammation was observed in only $20 \%$ of the samples addicted to inhaled opiate and was not found in the other groups. No significant differences were found in the severity of perivascular and peribronchial inflammation across the three groups. Although the mean of total inflammation scale in the subjects with oral opiate dependence $(3.00 \pm 1.79)$ was numerically higher than that in the inhaled dependence group $(1.40 \pm 2.60)$ and the controls $(2.25 \pm 1.26)$, this difference was not statistically significant.

Conclusions: Administration did not influence the appearance or severity of pulmonary inflammation in animal models addicted to opiate.
\end{abstract}

Keywords: Opiate Dependence; pulmonary Inflammation; Naloxone

\section{Background}

Serious health problems and socioeconomic consequences of the illicit use of opiates have been proved in both developed and developing societies. Based on the published reports, more than 15 million adults, or about 0.4 percent of the world's adult population, were estimated to be using these drugs in the early 2000s. In addition, illnesses and deaths due to the illicit opiate use were estimated to account for 0.7 percent of global disability-adjusted life years in 2000 (1). Thus, opiate use is a significant cause of premature mortality and morbidity among adults with a physical and mental heavy burden. Besides its socioeconomical effects, its triggering role on disabling disorders such as cardiovascular disor- ders has been suggested $(2,3)$. Furthermore, regarding suppressive influences of opium addiction on immune system, it have been shown that exogenous opioids tend to suppress the immune system and this negative modulation of immune cells depends on the opioid, its dose and the route of administration (4). For instance, opium can impair granulocyte aggregation and suppresses intracellular killing mechanisms in activated monocytes as well as appears to decrease the immune response by lowering chemotaxis and cell adherence (5). In animal models, opium administration can be associated with alterations in a number of immune parameters such as natural killer cells activity, proliferation of lymphocytes, antibody production and interferon production(6-8). Moreover, most of these immunosuppressive effects can

Implication for health policy/practice/research/medical education:

Severe perivascular inflammation was detected in $33.3 \%$ of the samples with oral opiate addiction and $20 \%$ of the cases addicted to opiate through inhalation. Also, severe peribronchial inflammation was observed only in $20 \%$ of the samples addicted to inhaled opiate and was not found in other groups. No significant differences were found in the severity of perivascular and peribronchial inflammation across the three groups. Although the mean of total inflammation scale in the subjects with oral opiate dependence ( $3.00 \pm 1.79)$ was numerically higher than that in the inhaled addiction group (1.40 \pm 2.60$)$ and the controls $(2.25 \pm 1.26)$, this difference was not statistically significant.

Copyright (C) 2013, Iranian Red Crescent Medical Journal; Licensee Kowsar Corp. This is an Open Access article distributed under the terms of the Creative Commons Attribution License (http://creativecommons.org/licenses/by/3.0), which permits unrestricted use, distribution, and reproduction in any medium, provided the original work is properly cited. 
be blocked by opioid antagonists (9). Despite confirmed adverse effects of opium use on immune pathways and cells, its impact on pulmonary function parameters and its immune systems is already questioned. Although some studies implicated opium use as the most likely responsible factor for lowering lung functional capacity in comparison with normal (10), but some others could not indicate its destructive effects on lung volume and compliance (11). Also, effects of different routes of opium administration as a main influencing factor on immune destructive process have not been cleared. Based on an experimental study, we tried to test this hypothesis that the route of opium administration has a major role in the progression of inflammation and its severity in pulmonary system.

\section{Objectives}

We aimed to evaluate "The effects of opiate addiction through different administration routes on pulmonary inflammation and its severity."

\section{Materials and Methods}

Our experiments were performed on 18 adult male Syrian golden hamsters, weighting 90-110 gr. Animals were kept at constant ambient temperature $\left(22^{\circ} \mathrm{C} \pm 1^{\circ} \mathrm{C}\right)$, under a 12-hour light/dark cycle with free access to food and water for two weeks. Then, hamsters were allocated to one of three groups $(n=6)$ : control group which did not receive opiate; the first study group were administered oral opiate twice a day via stomach tube; and another study group were administered inhaled opiate twice daily. In order to induce oral addiction to opiate, hamsters were addicted to opium through the use of increasing concentrations of opium $(0.1,0.2,0.3$, and $0.4 \mathrm{mg} / \mathrm{mL})$ in their water over three 48-hour periods. For inhaled dependence to opiate, hamsters were transferred to a closed room in order to inhale opiate twice a day in the same periods.

Opium addiction was tested by the injection of Naloxane $(2 \mathrm{mg} / \mathrm{Kg}, \mathrm{SC})$ and the appearance of the withdrawal syndrome. After four weeks, all hamsters were anesthetized with diethyl ether and their lung tissues were isolated for pathological assessment. A random number was assigned to each hematoxylin and eosin-stained lung section from the treatment and control groups. A pathologist blinded to the random numbers evaluated the slides for the degree of inflammation. The degree of peribronchial and perivascular inflammation was evaluated on a subjective scale of $0,1,2$, and 3 , corresponding to the following severity level: 0) no inflammation; 1) occasional cuffing with inflammatory cells; 2) bronchi or vessels surrounded by a thin layer (1-5 cells thick) of inflammatory cells; and 3) bronchi or vessels were surrounded by a thick layer (more than 5 cells thick) of inflammatory cells. The total lung inflammation was defined as the sum of peribronchial and perivascular inflammation scores $(12,13)$. Results were reported as mean \pm standard devia- tion (SD) for quantitative variables and percentages for categorical variables. The groups were compared using the One-way ANOVA test or Kruskal-Walis H test for continuous variables, and the chi-square test or Fisher's exact test if required for categorical variables. P values of 0.05 or less were considered statistically significant. All the statistical analyses were performed using SPSS version 16.0 (SPSS Inc., Chicago, IL, USA) for Windows.

\section{Results}

While preparing the tissues, three isolated samples in the control group were destructed and thus were excluded from the study. Severe perivascular inflammation was detected in $33.3 \%$ of the samples with oral opiate dependence and $20 \%$ of the cases addicted to opiate through inhalation, while, severe perivascular inflammation was not observed in the control group (Figure 1). Besides, this type of inflammation was not found in $60 \%$ of hamsters in the groups administered inhaled opiate and $25 \%$ of those in the control group. No significant difference was found in the severity of perivascular inflammation across the three groups $(\mathrm{P}=0.302)$. Regarding the appearance of peribronchial inflammation and its level (Figure 2), severe peribronchial inflammation was observed only in $20 \%$ of the subjects addicted to inhaled opiate and was not found in other groups, whereas mild to moderate peribronchial inflammation was revealed in $66.6 \%$ of the oral addicted group and in $100 \%$ of the control group. No difference was also found in the severity of peribronchial inflammation between the three study groups $(\mathrm{P}=0.088)$. Although the mean of total inflammation scale in the subjects with oral opiate dependence $(3.00 \pm 1.79)$ was numerically higher than that in the inhaled dependence group (1.40 \pm 2.60$)$ and the controls (2.25 \pm 1.26$)$, this difference was not statistically significant $(\mathrm{P}=0.442)$ (Figure 3 ).

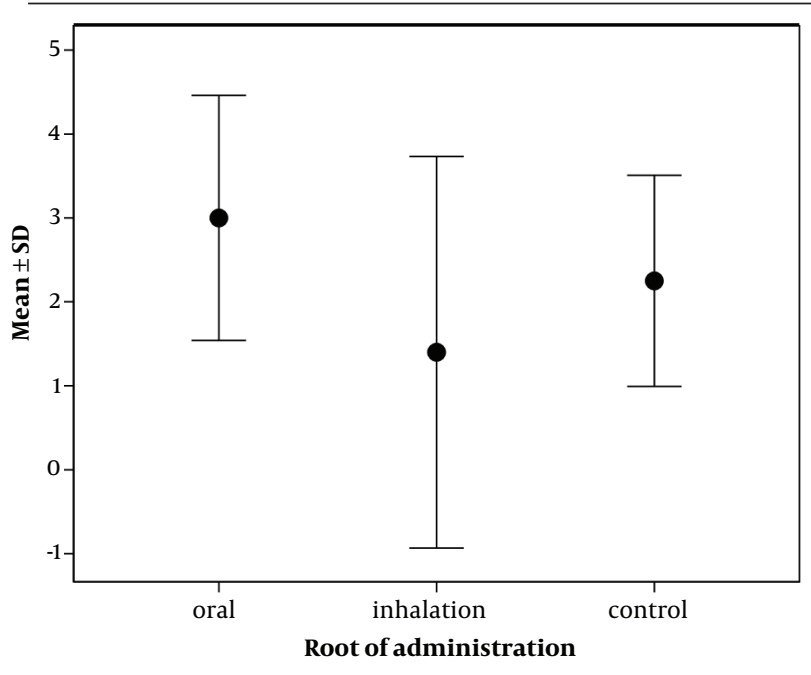

Figure 1. Severity of Perivascular Inflammation in Groups Addicted to Oral and Inhaled Opiate as well as the Control Group 


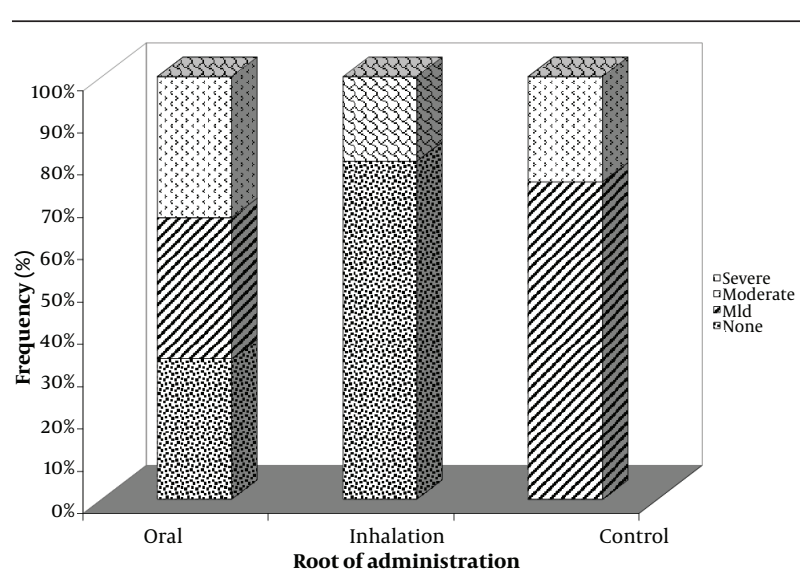

Figure 2. Severity of Peribronchial Inflammation in Groups Addicted to Oral and Inhaled Opiate as well as the Control Group

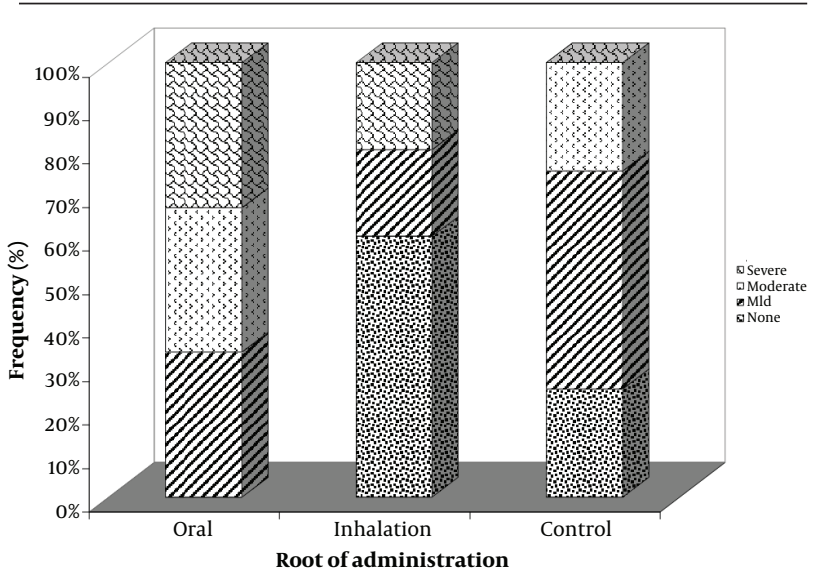

Figure 3. Mean of Total Inflammation Scale in the Groups Addicted to Oral and Inhaled

\section{Discussion}

Effects of opiates on inflammatory processes have been considered in several experimental systems. Most data were collected during experiments on the elicited paw inflammation in rats and mice (14-19). However, only a few investigations were performed on experimental pulmonary inflammation. The current study came to address the effects of opiates through different administration routes on inflammation and its severity. Our survey had two important findings. First, we showed that opiates in our selected dosage had no significant effects on the appearance of the inflammation as well as on its pathological severity. In fact, the level of pulmonary perivascular and peribronchial inflammation was similar across the study and the control groups. Second, we revealed that the route of administration had no critical role in the determination of the inflammation severity in the pulmonary system. Previously, it was emphasized the triggering role of opiates on inflammatory processes in vital organs. But nowadays, the obtained results has been suggesting a specific modulatory anti-inflammatory role of these substances in the acute inflammatory responses of the animal models $(19,20)$.

Even, recent studies suggest that peripheral morphine, the most applied opium, may be useful for the clinical management of acute inflammatory disorders (21). Moreover, significant increased concentrations of endogenous opioids in the serum of patients with systemic infection, particularly secreted from neutrophils during sepsis can emphasize the protective role of opiates in inflammatory processes (22). It is believed that low-dose opium might decrease the number of inflammatory leukocytes by inhibiting their migration from hemopoietic sites. The inhibitory effects of morphine on both the cell number and chemoattractant level are completely reversed by the naltrexone pretreatment, which implicates the involvement of opioid receptors (23). Opiates can also interact with interleukins and may act as signaling molecules between immunologically active cells. On the other hand, exogenous opioids tend to suppress the immune system; information on infections in opioid addicts suggest that this has clinical significance (24).However, it should be noticed that the administration of opiates with higher dosages might potentially lead to life-threatening immunosuppression. In addition, besides its psychological and social side effects, opium misuse can adversely affect other vital organs, including cardiovascular or cerebrovascular system that has been previously demonstrated. Totally, our study did not confirm the protective or triggering role of opiate dependence through different administration routes and also did not demonstrate its influence on the severity of pulmonary inflammation. However, more studies on animal models are recommended to confirm current findings.

\section{Acknowledgements}

We are thankfull from Kerman University of Medical Sciences.

\section{Authors' Contribution}

None declared.

\section{Financial Disclosure}

None declared.

\section{Funding/Support}

None declared. 


\section{References}

1. Hall W, Doran C, Degenhardt L, Shepard D, Jamison DT, Breman JG, Measham AR, Alleyne G, Claeson M, Evans DB, et al. Illicit Opiate abuse. In: Hall W, Doran C, Degenhardt L, Shepard D, Jamison DT, Breman JG, Measham AR, Alleyne G, Claeson M, Evans DB, et al, editors. Disease Control Priorities in Developing Countries.: Oxford University Press; 2006. p. 907-931.

2. Masoumi M, Shahesmaeili A, Mirzazadeh A, Tavakoli M, Ali AZ. Opium addiction and severity of coronary artery disease: a casecontrol study. J Res Med Sci. 2010;15(1):27-32.

3. Sadeghian S, Karimi A, Dowlatshahi S, Ahmadi SH, Davoodi S, Marzban M, et al. The association of opium dependence and postoperative complications following coronary artery bypass graft surgery: a propensity-matched study. J Opioid Manag. 2009;5(6):365-72.

4. Olson GA, Olson RD, Kastin AJ. Endogenous opiates: 1995. Peptides. 1996;17(8):1421-1466.

5. Carr DJ. The role of endogenous opioids and their receptors in the immune system. Proc Soc Exp Biol Med.1991;198(2):710-20.

6. Bryant HU, Roudebush RE. Suppressive effects of morphine pellet implants on in vivo parameters of immune function.J Pharmacol Exp Ther.1990;255(2):410-4.

7. Lysle DT, Hoffman KE, Dykstra LA. Evidence for the involvement of the caudal region of the periaqueductal gray in a subset of morphine-induced alterations of immune status. I Pharmacol Exp Ther.1996;277(3):1533-40.

8. Taub DD, Eisenstein TK, Geller EB, Adler MW, Rogers TJ. Immunomodulatory activity of mu- and kappa-selective opioid agonists. Proc Natl Acad Sci U S A. 1991;88(2):360-4.

9. Carr DIJ, Radulescu RT, DeCosta BR, Rice KC, Blalock JE. Differential effect of opioids on immunoglobulin production by lymphocytes isolated from Peyer's patches and spleen. Life sciences. 1990;47(12):1059-1069.

10. Koon LH, Chuan PS, Gandevia B. Ventilatory capacity in a group of opium smokers. Singapore Med J.1970;11(2):75-9.

11. Javadi H, Ahmadi A. Relation between opium smoking and pulmonary function. J Qazvin Univ Med Sci. 2004;29:.

12. Kwak YG, Song CH, Yi HK, Hwang PH, Kim JS, Lee KS, et al. Involvement of PTEN in airway hyperresponsiveness and inflammation in bronchial asthma. J Clin Invest. 2003;111(7):1083-92.
13. Sur S, Wild JS, Choudhury BK, Sur N, Alam R, Klinman DM. Long term prevention of allergic lung inflammation in a mouse model of asthma by CpG oligodeoxynucleotides. J Immunol. 1999;162(10):6284-93.

14. Herz A. Role of immune processes in peripheral opioid analgesia. Adv Exp Med Biol.1995;373:193-9.

15. Ossipov MH, Kovelowski CJ, Porreca F. The increase in morphine antinociceptive potency produced by carrageenan-induced hindpaw inflammation is blocked by naltrindole, a selective $\delta$-opioid antagonist. Neurosci Lett. 1995;184(3):173-176.

16. Stein C, Hassan AH, Przewlocki R, Gramsch C, Peter K, Herz A Opioids from immunocytes interact with receptors on sensory nerves to inhibit nociception in inflammation. Proc Natl Acad Sci US A. 1990;87(15):5935-9.

17. Stein C, Millan MJ, Yassouridis A, Herz A. Antinociceptive effects of $\mu$ - and $\kappa$-agonists in inflammation are enhanced by a peripheral opioid receptor-specific mechanism. Eur. J. Pharmacol. 1988;155(3):255-264.

18. Suzuki T, Kishimoto Y, Misawa M. Formalin- and carrageenan induced inflammation attenuates place preferences produced by morphine, methamphetamine and cocaine. Life Sci. 1996;59(19):1667-1674.

19. Zeitune MG, Bazerque E, Bazerque PM. Specific opiate effects on dextran-induced inflammation in rats. Acta Physiol Pharmacol Ther Latinoam. 1991;41(3):349-58.

20. van Loon JP, de Grauw JC, van Dierendonck M, L'Ami J J, Back W, van Weeren PR. Intra-articular opioid analgesia is effective in reducing pain and inflammation in an equine LPS induced synovitis model. Equine Vet J. 2010;42(5):412-9.

21. Perrot S, Guilbaud G, Kayser V. Effects of intraplantar morphine on paw edema and pain-related behaviour in a rat model of repeated acute inflammation. Pain.1999;83(2):249-257.

22. Glattard E, Welters ID, Lavaux T, Muller AH, Laux A, Zhang D, et al. Endogenous morphine levels are increased in sepsis: a partial implication of neutrophils. PLoS One. 2010;5(1):e8791.

23. Chadzinska M, Kolaczkowska E, Seljelid R, Plytycz B. Morphine modulation of peritoneal inflammation in Atlantic salmon and CB6 mice. J Leukoc Biol.1999;65(5):590-6.

24. Kranjnik M, Finlay IG, Zylicz Z. affect inflammation and the immune system. Pain Reviews.1998;5(3):147-154. 